\title{
Epidemiological Study of Clinical and Laboratory Profiles of Patients with Acute Lymphoblastic Leukemia at Dr. Soetomo Hospital Surabaya
}

\author{
Kezia Warokka Putri ${ }^{1}$, I Dewa Gede Ugrasena ${ }^{2 *}$, Yetti Hernaningsih ${ }^{3}$ \\ ${ }^{1}$ Faculty of Medicine, Universitas Airlangga, Surabaya, Indonesia \\ ${ }^{2}$ Department of Pediatric, Faculty of Medicine, Universitas Airlangga, Surabaya, Indonesia - Dr. Soetomo General Hospital \\ Surabaya, Indonesia \\ ${ }^{3}$ Department of Clinical Pathology, Faculty of Medicine, Universitas Airlangga, Surabaya, Indonesia - Dr. Soetomo General \\ Hospital Surabaya, Indonesia
}

\section{A R T I C L E I N F O}

\section{Article history:}

Received 5 May 2019

Received in revised form 10 June

2019

Accepted 25 June 2019

Available online 30 June 2019

\section{Keywords:}

Acute Lymphoblastic Leukemia,

Clinical Profile,

Epidemiology.

*) Corresponding author: ugrasena56@gmail.com

\begin{abstract}
A B S T R A C T
Introduction: Considering the high number of acute lymphoblastic leukemia (ALL) and it being the type of cancer with the highest fatality rate among the children, this study seeks to determine the epidemiological description of the clinical and laboratory profiles of patients with ALL.

Methods: This research used a descriptive study by using medical data record of patients with ALL. The research variables were gender, age, leukemia history of the patient's family, nutritional status, symptoms and signs, laboratory examination, ALL subtypes, risk factors, and result outcomes. All data presented descriptively.

Results: From a total of 50 patients, $54 \%$ of them were male aged $1,5-10$ years old. $84 \%$ of the patients' family had no medical record related to leukemia. $42 \%$ of the patient malnutrition. Pale $(78 \%)$, fever $(64 \%)$, pain $(32 \%)$, hepatomegaly $(38 \%)$, lymphadenopathy $(28 \%)$, splenomegaly (26\%), patients with anemia (82\%), leukocytosis $(38 \%)$, thrombocytopenia $(54 \%)$. The highest types were ALL-LI (68\%), SR-ALL (54\%), and remission outcome reached $82 \%$.

Conclusion: Insidence higher in male, aged 1,5 - 10 years old, malnourished at the start of the diagnosis. Most of the patients' family had no medical history of leukemia. Symptoms and medical signs mostly appeared were pale, fever, and bone/joint pain. The physical examination showed hepatomegaly, lymphadenopathy, and splenomegaly and laboratory first test showed the patients had anemia, leukocytosis, and thrombocytopenia.
\end{abstract}

\section{Introduction}

Acute diarrhea Traditional medicine and herbal are two of Acute lymphoblastic leukemia (ALL) is the most common cancer in children and adolescents with more than 3,000 new cases each year. The American Cancer Society (2017), estimates there are 5,970 new cases of ALL in adults and children consisting of 3,350 men and 2,620 women. An estimated 1,440 deaths from this disease (800 in men and 640 in women). The National Cancer Institute estimates that in 2018 as many as 60,300 people will live with ALL. ${ }^{1}$ The highest ALL incidence is in children aged 2-5 years with an average incidence of 4-4.5 cases/year/ 100,000 children under 15 years of age.

The FAB system defines three categories of lymphoblasts. L1 lymphoblasts are usually smaller, with scant cytoplasm and inconspicuous nucleoli. Cells of the
L2 variety are larger, and they demonstrate considerable heterogeneity in size, prominent nucleoli, and more abundant cytoplasm. Lymphoblasts of the L3 type, notable for their deep cytoplasmic basophilia, are large, frequently display prominent cytoplasmic vacuolation, and are morphologically identical to Burkitt's lymphoma cells. ${ }^{2}$

ALL is a neoplastic disease as a result of somatic mutations in several stages in a lymphoid progenitor cell in one of several stages of development. ${ }^{3}$ Males have a worse prognosis than female. ${ }^{4}$ The Academy of Sciences reported a fivefold increase in cancer risk was found in children exposed to radiation in the first trimester. Other factors studied which are the possible causes of ALL include parents who smoke, use of herbicides and pesticides, the military experience of parents where they are susceptible to chemicals, alcohol use, maternal 
contraception, diethylstilbestrol, household radon exposure, and chemical contamination of groundwater. The frequency of leukemia is higher in families patienting from the same condition. Siblings with ALL have approximately twice to four times tend to have more disease developing than the general population.

Several studies have shown that the incidence of malnutrition in children who patient from ALL tends to increase threefold compared to children who are healthy/ have no history of cancer. ${ }^{5}$ ALL accounts about $80 \%$ of leukemia cases in children, it is important to conduct scientific research to improve understanding of the epidemiology, signs and symptoms, prognostic factor, hence children with ALL can be immediately detected and treated.

\section{Methods}

This research used the descriptive study by using medical data record of patients with ALL at Department of Pediatrics Dr. Soetomo Hospital Surabaya from January- December 2016 using total sampling. The inclusion criteria of this study were all patients aged 0-18 years old who were first diagnosed as ALL and have complete medical record data, while incomplete medical record data were excluded. We collected data regarding gender, age, family history of leukemia, initial nutritional status using the WHO 2005 chart (body weight/height) for 0-5 years and CDC 2000 curve for ages $>5$ years, clinical symptoms and signs, laboratory assessment, description of cell morphology of hospital examination based on FAB (French-America-British). We determined risk classification based on age, initial leukocyte count, central nervous system status, and outcomes. All data collected presented as descriptive analysis.

\section{Results}

From a total of 216 patients with ALL in 2016, 50 data met the inclusion criteria. The number of exclusion data was 114 medical documents, 132 patients underwent therapy, 11 people ALL relapsed, 4 people with a diagnosis, and 33 data were incomplete, data the remaining data was not found in the medical record archive.

Within one year there were 50 new patients diagnosed with ALL, 27 people (54\%) including male and the remaining 23 people $(46 \%)$ female, with a ratio of 1.17 . The average age of the patient at the time of initial diagnosis is 6.5 years of age, with the youngest age being 1 year while the oldest age is 17 years. Most patient families (84\%) do not have a history of leukemia. However, one patient showed a history of leukemia in his twin brother. Children with malnutrition as many as 21 people $(42 \%)$ were found most at diagnosis.

While the remaining 20 patients $(40 \%)$ with adequate nutrition, 8 patients $(16 \%)$ with overnutrition, and 1 patient $(2 \%)$ with no data. Based on risk classification, the average patient was included in the standard risk with as many as 27 people $(54 \%)$ while the rest were 23 people with high risk (46\%). The cell morphology based on FAB was obtained, lymphoblasts L1 (68\%) were small in size with little cytoplasm; in L2 cells (18\%) larger and pleomorphic with multiple cytoplasm, irregular core shape, and real nuclei; and L3 cells $(0 \%)$ have fine spotted homogeneous core chromatin, clear nuclei, and dark blue cytoplasm with real vacuoles. Although the FAB classification system appears to have value as a prognostic indicator, there is no biological basis for the morphologic differences delineated by this system has been identified. Generally, the most important morphologic distinctions are those between ALL and AML5 . Results of patient outcomes in remission were 41 people $(82 \%)$, drop out 4 people $(8 \%)$, and died 5 people $(10 \%)$ due to infection in ( 1 person), bleeding ( 1 person), pneumonia (1 person), and brain edema (1 person). Details are listed in Table 1.

Table 1 Baseline data of ALL patients in Pathology Hematology-Oncology Departments / SMF Child Health Dr. Soetomo Hospital Surabaya in 2016

\begin{tabular}{|c|c|c|}
\hline Variable & $\mathbf{n}=\mathbf{5 0}$ & $\%$ \\
\hline Sex & Frequency & \\
\hline Male & 27 & 54 \\
\hline Female & 23 & 46 \\
\hline \multicolumn{3}{|l|}{ Age } \\
\hline$<1,5$ & 5 & 10 \\
\hline $1,5-10$ & 31 & 62 \\
\hline$>10$ & 14 & 28 \\
\hline \multicolumn{3}{|l|}{ Family History } \\
\hline Yes & 1 & 2 \\
\hline No & 42 & 84 \\
\hline No data & 7 & 14 \\
\hline \multicolumn{3}{|l|}{ Nutritional Status } \\
\hline Malnourished & 21 & 42 \\
\hline Well-nourished & 20 & 40 \\
\hline Overnutrition & 8 & 16 \\
\hline \multicolumn{3}{|l|}{ Risk Classification } \\
\hline Standard Risk & 27 & 54 \\
\hline High Risk & 23 & 46 \\
\hline \multicolumn{3}{|l|}{ Subtype ALL } \\
\hline L1 & 34 & 68 \\
\hline $\mathrm{L} 2$ & 9 & 18 \\
\hline L3 & 0 & $\mathbf{0}$ \\
\hline No data & 7 & 14 \\
\hline \multicolumn{3}{|l|}{ Outcome } \\
\hline Remission & 41 & 82 \\
\hline Drop out & 4 & 8 \\
\hline Died & 5 & 10 \\
\hline
\end{tabular}

Most of the patient's signs and symptoms at diagnosis pale $(78 \%)$, fever $(64 \%)$ with a temperature $38-40^{\circ}$ $(60 \%)$, temperature $>40^{\circ} \mathrm{C}(4 \%)$, no data $(20 \%)$. In addition, patients also experience other complaints such as bone/joint pain (28\%), weakness (28\%), gum bleeding (24\%), petechiae/purpura (16\%). Hepatomegaly (38\%), lymphadenopathy (28\%), and splenomegaly (26\%) in some patients. Details are listed in Figure 1. Laboratory images at the time of diagnosis were anemia (82\%), leukocytosis (38\%), and thrombocytopenia (54\%) in ALL patients. Details are listed in Table 2. 
Table 2 Laboratory examination of ALL patients in Pathology Hematology-Oncology Departments / SMF Child Health Dr. Soetomo Hospital Surabaya in the early diagnosis

\begin{tabular}{lcc}
\hline \multicolumn{1}{c}{ Variable } & $\mathrm{n}=50$ & $\%$ \\
\hline $\mathrm{Hb}$ & Frequency & \\
$<5$ & 8 & 16 \\
$5-10$ & 33 & 66 \\
$>10$ & 9 & 18 \\
\hline Leukocytes & & \\
$<4.000$ & 16 & 32 \\
$4.000-15.000$ & 15 & 30 \\
$15.000-50.000$ & 10 & 20 \\
$>50.000$ & 9 & 18 \\
\hline Platelets & & 54 \\
$<50.000$ & 27 & 30 \\
$50.000-150.000$ & 15 & \\
\hline
\end{tabular}

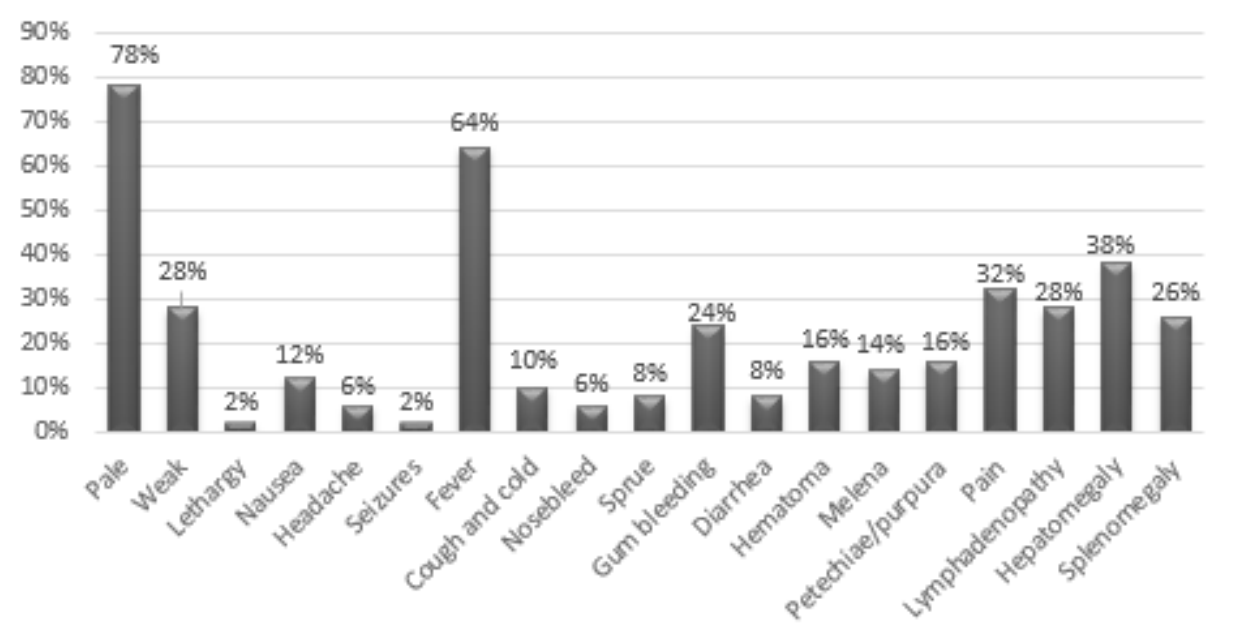

Figure 1 Clinical symptoms and signs of ALL patients in Pathology Hematology-Oncology Departments / SMF Child Health Dr. Soetomo Hospital Surabaya in the early diagnosis

\section{Discussion}

Based on the results of the study, of the 50 pediatric patients with ALL, male dan female ratio was 1.17 , which is in line with a previous study 6. It is stated that male dominance in ALL due to the role of sex hormones in leukemogenesis, but there is still no strong evidence. One recent study in a population with relative genetic homogeneity (the French population of Quebec) demonstrated an increased risk for children with a particular set of glutathione S-transferase (GST) and cytochrome P-450 alleles. A protective effect for female was associated with the presence of a specific $\mathrm{P}-450$ allele. It is suggested that there is an association between a certain HLA-DR haplotype (HLA-DRB4*01) and a particular mutation $(\mathrm{C} 282 \mathrm{Y})$ in the HFE gene (associated with hereditary hemochromatosis) and an increased risk for male developing ALL . ${ }^{5}$

Age is a significant prognostic factor in ALL patients. In patients aged 2 - 5 years the survival rate is two times greater than patients aged less than 2 years or more than 10 years 2 . In this study, the incidence of ALL was highest in children aged $1.5-10$ years $(62 \%)$. ALL in infants have a high mortality rate. ${ }^{5}$

Most of the $84 \%(n=42)$ families of patients did not have a history of leukemia in the family. However, one patient has a twin with leukemia. Acute leukemia in twin monozygotes is estimated at $25 \%$. The highest risk of twins either mono or heterozygous is in childhood and after 7 years of age.$^{5}$ It was believed that the high risk found in ALL twins resulted from blood circulation which was divided prenatally. ${ }^{7}$

A total of 21 people (42\%) were found with malnutrition at diagnosis. This result is in accordance with the research in Manado during the period 20062013 , found the frequency of patient with malnutrition as many as $54.8 \%$. On the other hand, results in Yogyakarta showed most of the patients have good nutritional status 29 (69\%). Some studies have suggested that nutritional status is a significant prognostic factor. One study showed that malnutrition was a significant predictor of treatment failure. It has also been reported that children who were malnourished will have less tolerance for chemotherapy and received suboptimal doses. ${ }^{5}$

Children with ALL usually show symptoms that are 
not specific so that ALL can look like other diseases. ${ }^{5}$ Based on the results of the study, the main complaints felt by patients were pale $78 \%(n=39), 64 \%$ fever $(n$ $=32)$, and weak $28 \%(\mathrm{n}=14)$. These results are in accordance with research at the Oncology Center of AlBatool Teaching Hospital in Iraq, as many as 55 patients also had dominant symptoms of fever $(81.8 \%)$ and pale $(67.3 \%) 8$. About $50 \%$ of patients present with fever, originating from infection caused by neutropenia or leukemia cells that release cytokines such as interleukin (IL)-1, IL-6, and tumor necrosis factors (TNFs). ${ }^{3}$ Laboratory features in leukemic patients vary from mild to severe. In this study, hemoglobin was found to vary between $2.5 \mathrm{~g} / \mathrm{dl}$ to $13.8 \mathrm{~g} / \mathrm{dl}$, with the dominance of $5-10 \mathrm{~g} / \mathrm{dl} \mathrm{Hb}$ of $66 \%(\mathrm{n}=33)$. The loss of bone marrow function is due to the progressive infiltration of white blood cells into the bone marrow, thus the bone marrow cannot produce properly.

In addition, in this study, other complaints were found, such as 14 patients with joint pain. Bone pain, especially in the long bones, indicates the involvement of periosteal and bone leukemia. This is due to the presence of bone marrow infiltration by cells from leukemia. One of the factors that caused the occurrence of bone pain in patients, one of which was in the early ALL event the cells in the bone marrow were still normal.

On physical examination results found 38\% hepatomegaly $(n=19), 28 \%$ lymphadenopathy $(n=14)$, and $26 \%$ splenomegaly $(n=13)$. Hepatosplenomegaly usually occurs in two thirds of patients and is usually unconscious (asymptomatic). ${ }^{5}$ Lymphadenopathy and hepatosplenomegaly arise due to the extramedular invasion of leukemic cells 2. Variations in the infiltration of leukemia cells into organs are related to the time of diagnosis. ${ }^{6}$ Hepatomegaly often occurs in patients with hemoglobin $<10 \mathrm{~g} / \mathrm{dl}$. In diseases that arise more slowly, hepatomegaly is followed by splenomegaly, lymphadenopathy, and hyperleukocytosis. ${ }^{2}$

The leukocyte levels in this study varied from 1,300 to $352,000 / \mathrm{mm}^{3}$. Eight patients experienced hyperleukocytosis with leukocytes $>150,000 / \mathrm{mm}^{3}$. Edge blood tests alone cannot be a definitive diagnosis in cases of leukemia. When the results of peripheral blood tests lead to leukemia, then bone marrow examination, immunophenotypes, and cytogenetics must be carried out immediately to make a diagnosis. ${ }^{6}$ Our result found 42 patients $(84 \%)$ with thrombocytopenia, as one of hematopoiesis dysfunction results. Signs and symptoms related to bleeding such as melena, petechiae, bruising, nosebleed, or purpura. The severity and the degree of bleeding correlate with the degree of thrombocytopenia. Severe hemorrhage is rare even with platelet counts less than 20,000 per $\mathrm{mm}^{3}$ unless fever and infection, both of which can affect platelet survival and function, are present. ${ }^{5}$ Anemia, leukocytosis or leukopenia, thrombocytopenia, enlargement of the liver or spleen, bone pain, fever, or a sudden decrease in tolerance to continuation chemotherapy may signal the onset of marrow relapse. ${ }^{3}$

From the results of the study, found L1 subtypes $68 \%(\mathrm{n}=34)$, L2 18\% $(\mathrm{n}=9)$, and L3 0\%. L1 subtypes are more common than L2 ALL subtypes6. The EpsteinBarr virus (EBV) has been linked to cases of endemic Burkitt's lymphoma, the L3 morphologic subtype of ALL, and some cases of Hodgkin's disease. L2 subtype is more common in adults. Lymphoblasts of the L3 type possess cell surface immunoglobulin and other characteristic B-cell markers. L1 morphology has been associated with a higher remission induction rate and better event-free survival (EFS) than L2 morphology, which appears to convey a poor prognosis. In early studies, L2 morphology appeared to be an independent prognostic variable indicative of poor outcome. In more recent studies, however, it sometimes loses its predictive value when the patients are stratified for age, sex, and diagnostic white count. Patients with the L3 morphology have the worst overall prognosis. ${ }^{5}$

Based on the results of the study, it was found that $54 \%(\mathrm{n}=27)$ ALL pediatric patients with standard risk and $46 \%(\mathrm{n}=23)$ patients with high risk. Age, gender, and initial leukocyte count are important in prognostic factors. ${ }^{9}$ The literature has noted a poor prognostic in children $>10$ years and $\mathrm{WBC}>50,000 / \mathrm{mm}^{3} .{ }^{10} \mathrm{ALL}$ patients with a high risk of dying were twice as large as those of standard risk patients. ${ }^{2}$ There were 41 remission patients, 4 patients dropped out, and the rest died. Five patients died from an infection, bleeding, pneumonia, acute pancreatitis, and brain edema. In research, febril neutropenia was the most common complication associated with infection, followed by upper respiratory tract infections, ears, blood flow, and gastrointestinal tract. $^{11}$

\section{Conclusion}

Acute lymphoblastic leukemia in childhood is often found at 1,5-10 of age, male, with no history of leukemia in the family. The most cell morphology subtype was L1, standard risk ALL, and results in outcome of remission patients. Most symptoms and clinical signs are pale, fever, weak. On physical examination found hepatomegaly, splenomegaly, and lymphadenopathy in $20-40 \%$ of patients. Most laboratory examinations of patients with anemia, leukocytosis, and thrombocytopenia.

\section{Conflict of Interest}

The author stated there is no conflict of interest

\section{References}

1. Ward E, DeSantis C, Robbins A, Kohler B and Jemal A. Childhood and adolescent cancer statistics, 2014. CA: A Cancer Journal for Clinicians. 2014; 64: 83-103.

2. Widiaskara I, Permono B, Ugrasena I and Ratwita M. Luaran Pengobatan Fase Induksi Pasien Leukemia Limfoblastik Akut pada Anak di Rumah Sakit Umum Dr. Soetomo Surabaya. Sari Pediatri. 2016; 12: 128-34

3. Kaushansky K, and more. Williams Hematology (9th Ed.). 2016.

4. Hunger SP, Lu X, Devidas M, et al. Improved Survival for Children and Adolescents with Acute Lymphoblastic Leukemia between 1990 and 2005: a Report from the Children's Oncology Group. Journal of Clinical Oncology. 2012; 30: 1663.

5. Pizzo PA and Poplack DG. Principles and Practice of Pediatric Oncology. Lippincott Williams \& Wilkins, 2015.

6. Jatav J, Jain B and Niranjan AK. Clinicopathological Study of Acute Lymphoblastic Leukemia-a Multiparameter Study. Cough. 2015; 2: 5.4 . 
7. Carceller E, Ruano D, Madero LL and Lassaletta Á. Two Siblings with Acute Lymphoblastic Leukaemia: Chance or Genetics? Anales de Pediatria (Barcelona, Spain: 2003). 2017, p. 170.

8. Shalal HH, Mahmood NS and Alchalabi MAQ. Clinical, Hematological, and Laboratory Presentation of Acute Lymphoblastic Leukemia of Children in Diyala Province/Eastern Iraq. 2017. 2017; 5: 7.

9. Pui C-H, Boyett J, Rivera G, et al. Long Term Results of Total Therapy Studies 11, 12 and 13A for Childhood Acute Lymphoblastic Leukemia at St Jude Children's Research Hospital. Leukemia. 2000; 14: 2286.
10. Pui CH, Robison LL and Look AT. Acute Lymphoblastic Leukaemia. Lancet (London, England). 2008; 371: 1030-43.

11. Inaba H, Pei D, Wolf J, et al. Infection Related Complications During Treatment for Childhood Acute Lymphoblastic Leukemia. Annals of Oncology. 2016; 28: 386-92. 